\title{
PROFESSORES FRENTE ÀS TECNOLOGIAS DE INFORMAÇÃO E COMUNICAÇÃO (TIC) DISPONÍVEIS NO PORTAL DIA-A-DIA EDUCAÇÃO
}

Jussany Maria de Barros Moreira, Dulcinéia Ester Pagani Gianotto

Programa de pós-graduação em Educação para a Ciência e a Matemática da Universidade Estadual de Maringá - UEM. Email: jussanymoreira@gmail.com

\section{RESUMO}

O artigo é resultado da pesquisa de mestrado, que está sendo realizada no programa de pósgraduação em Educação para a Ciência e a Matemática da Universidade Estadual de Maringá, tendo como um dos objetivos investigar, através da aplicação de um questionário, sete professores do Colégio Estadual de Pato Branco, sobre a utilização das Tecnologias de Informação e Comunicação (TIC) disponíveis no Portal dia-a-dia Educação do Estado do Paraná, bem como propor sua autoavaliação frente a utilização das Tecnologias de Informação e Comunicação (TIC) e analisar se eles acreditam que com o uso das tecnologias pode-se promover aprendizagem significativa. Conclui-se que a maior parte dos professores questionados relatam fazer um bom trabalho com seus alunos frente as TIC, porém, destacamos que apenas três deles acessam o Portal dia-a-dia Educação pelo menos uma vez por semana, mas todos acreditam que a utilização das TIC podem contribuir para uma motivação nas aulas e a uma aprendizagem significativa.

Palavras-chave: aprendizagem, professores, auto-avaliação, Tecnologia de Informação e Comunicação na educação, Portal dia-a-dia Educação.

\section{INTRODUÇÃO}

Neste artigo vamos discutir os resultados parciais de uma pesquisa de mestrado realizada no programa de pós-graduação em Educação para a Ciência e a Matemática da Universidade Estadual de Maringá. Através desta pesquisa pretendeu-se investigar como os professores se auto-avaliam frente à utilização das Tecnologias de Informação e Comunicação (TIC) disponíveis no Portal dia-adia Educação, com que freqüência acessam o Portal dia-a-dia Educação e se consideram que as TIC podem contribuir para uma aprendizagem significativa.

Destacando que pela integração das TIC no processo de ensino e aprendizagem, os professores podem aprender a dominar e a valorizar não só um novo instrumento, ou um novo sistema de representação do conhecimento, mas uma nova cultura de aprendizagem (COOL; MONEREO, 2010). Para tanto, o Estado do Paraná, com a implantação do programa Paraná Digital, o Portal dia-a-dia Educação, a TV Paulo Freire e a TV Multimídia vem estimulando e viabilizando a utilização das TIC. 


\title{
O professor frente às Tecnologias de Comunicação e Informação (TIC)
}

Uma boa formação inicial de professores, assim como sua continuidade são fundamentais para uma melhor qualidade no Ensino de Ciências, porém, para que possamos lidar com as transformações impostas pela sociedade, nos ancoramos nas novas competências profissionais que Perrenoud (2001) designa como capacidade de mobilizar recursos cognitivos para enfrentar determinadas situações, que são construídas na formação e na prática diária do professor. O autor, ao analisar essas competências, esclarece que uma cultura tecnológica de base, é necessária para pensar as relações entre a evolução dos instrumentos, as competências intelectuais e a relação com o saber que a escola pretende adotar, complementando que as mudanças submetidas pela informática às práticas de leitura e escrita não podem ser ignoradas pela escola, destacando que "a escola não pode ignorar o que se passa no mundo. Ora, as novas tecnologias da informação e da comunicação (TIC ou NTIC) transformam espetacularmente não só nossas maneiras de comunicar, mas também de trabalhar, de decidir, de pensar (PERRENOUD, 2000, p. 125)".

Ao incluir as TIC na educação, espera-se que as instituições de ensino e comunidade escolar (professores, alunos, pais e funcionários) almejem mudança pedagógica que passe

\begin{abstract}
"de uma educação totalmente baseada na transmissão da informação, na instrução, para a criação de ambientes de aprendizagem nos quais o aluno realiza atividades e constrói o seu conhecimento. Essa mudança acaba repercutindo em alterações na escola como um todo: na organização, na sala de aula, no papel do professor e dos alunos e na relação com o conhecimento (VALENTE, 1999, p. 31)."
\end{abstract}

Desta forma, o docente necessita se adequar à sociedade contemporânea e às rápidas mudanças ocasionadas tanto pelas descobertas científicas quanto pelas inovações tecnológicas, em que o saber ao atualizar-se rapidamente gera modificações nas ciências e nas técnicas, tornando-se o principal fator de transformação do modo de vida, de comunicação social e das relações de trabalho.

Sabe-se que a prática pedagógica do professor não deve se limitar à implantação momentânea, mas ser incorporada efetivamente no seu trabalho cotidiano e na sua formação continuada com dinamismo e com apoio governamental para dar norte à sua vida. Segundo Pimenta e Anastasiou (2005), as transformações das práticas docentes se concretizam na medida que o docente amplia sua consciência sobre a própria prática, o que implica conhecimentos sobre a realidade. 
Portanto, a escola, professores e alunos não podem mais ficar alheios às tecnologias presentes na sociedade. Precisam apoiar a presença de políticas educacionais, como ocorre no Estado do Paraná, com a criação do Portal dia-a-dia Educação.

\section{O Estado do Paraná e o Portal dia-a-dia Educação}

O Portal dia-a-dia Educação é uma ferramenta online que disponibiliza diversos recursos didáticos, conteúdos, informações e serviços em ambientes exclusivos, por intermédio de uma tecnologia rápida e direta da internet e com informações dispostas de acordo com os públicos-alvo específicos, tendo como finalidade atingir toda a comunidade educacional do Paraná. Foi criado de acordo com as justificativas trazidas pelo documento oficial do Programa das Nações Unidas para o Desenvolvimento (PNUD), referindo-se ao fato de que a qualidade do ensino passa a constituir-se a prioridade para os planos de intervenção do Governo Estadual.

De acordo com o contexto do documento (Projeto BRA/03/036 - Educação e Inclusão Digital no Estado do Paraná) compreende-se as tecnologias como veículo de disseminação das políticas públicas educacionais do Estado do Paraná, possibilitando o atendimento universal e simultâneo dos atores do sistema de ensino. Essa possibilidade se relaciona também à ideia de que o Portal diaa-dia Educação permitiria inserir os atores na Sociedade da Informação (SI), não apenas pela ampliação do acesso à Internet, mas principalmente porque saberiam fazer uso das TIC para tomar decisões referentes ao seu próprio conhecimento (PNUD, 2007).

Esse modelo de colaboração disponível no Portal dia-a-dia Educação possibilita aos professores inovar suas práticas pedagógicas, através da consulta, da pesquisa e troca de experiências com outros professores, permitindo ao professor acessar conteúdos já elaborados ou mesmo divulgar sua própria produção. Percebe-se, então, que os planejadores do projeto entendem que, por intermédio das TIC, é possível promover o resgate da identidade do professor da escola pública paranaense, propiciando a veiculação de sua produção intelectual e fomentando a criação de comunidades virtuais de aprendizagem (PARANÁ, 2006).

O governo do Paraná instituiu o Portal dia-a-dia Educação em 2003, sendo reformulado em 2011, possibilitando que diversos tipos de usuários acessem aos conteúdos que foram pensados e desenvolvidos especialmente para os quatro principais públicos: alunos, professores, gestores e comunidade escolar, conforme a Figura 1, sendo que em cada ambiente podemos encontrar novidades em conteúdos pedagógicos, fazer consultas, acessar o email, postar materiais no espaço colaborativo, baixar artigos, filmes, vídeos, entre outros. 


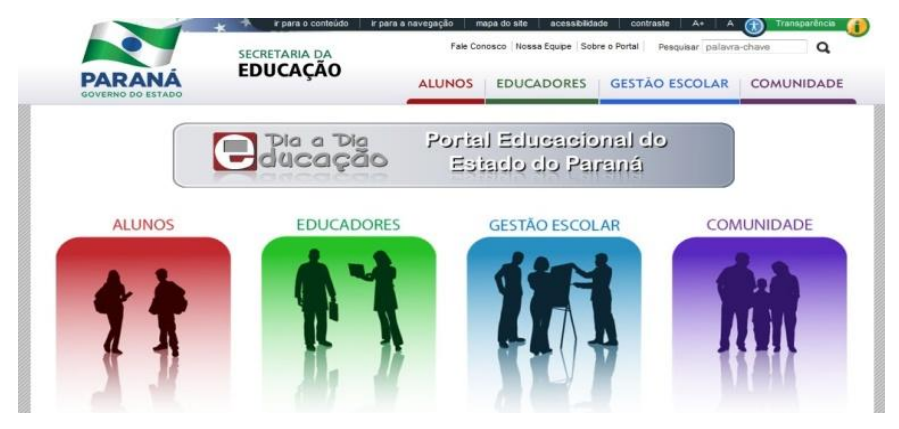

Figura 01. Portal dia-a-dia Educação

Fonte: www.diaadiaeducacao.pr.gov.br

Podemos acessar gratuitamente o Portal dia-a-dia Educação por meio da página www.diaadiaeducacao.pr.gov.br, onde estão disponibilizados diversos Objetos de Aprendizagem que poderão dar suporte à prática docente. Estes objetos de aprendizagem têm como fonte de criação: Intel Corporation, LabVirt, Portal do professor - MEC, CreativeCommonsLicense, etc. Esses recursos didáticos estão disponibilizados na página da disciplina, como podemos verificar na figura abaixo(02):

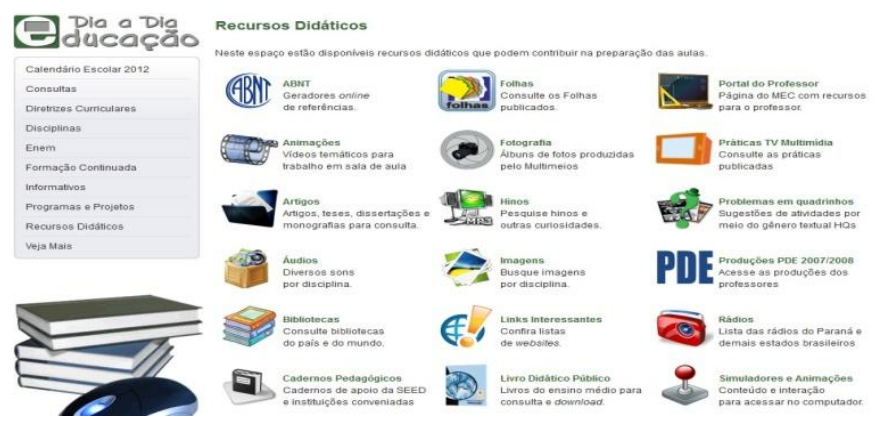

Figura 02. Recursos didáticos

Fonte: www.diaadiaeducacao.pr.gov.br

\section{METODOLOGIA}

Para desenvolver este trabalho fez-se uso da pesquisa qualitativa, por meio da utilização de um estudo de caso, que visa o exame detalhado de um ambiente, de um simples sujeito ou de uma situação particular (GODOY, 1995). Para a coleta de dados aplicou-se um questionário a sete professores que ministram aulas na educação básica do Colégio Estadual de Pato Branco, no município de Pato Branco-Pr. Entre eles, dois professores de Ciências (C1 e C2), dois de Química (Q1 e Q2), dois de Biologia (B1 e B2) e umde Física (F1). Os resultados foram discutidos pela análise do discurso e o número da aprovação no Conselho de Ética é 10220213.4.0000.0104. 


\section{RESULTADOS}

A seguir destacaremos os resultados obtidos referente a algumas das questões que foram aplicadas aos professores:

1. Faça uma auto-avaliação referente ao seu trabalho com os alunos frente às TIC que estão disponíveis no Portal dia-a-dia Educação?
( ) Excelente
( ) Ótimo
( ) Bom
( ) Regular

Respostas: C1, Q2, B1 e F1: bom; C2 e B2: regular; Q1: ótimo;

2. Com que freqüência você acessa o Portal dia-a-dia Educação?

( ) Uma vez por dia ( ) Três vezes por semana （）Uma vez por semana

( ) Quinzenalmente ( ) Uma vez por mês

Respostas: C1 e Q2: uma vez por semana; C2: uma vez por mês; Q1: uma vez por dia;

B1 e B2: uma vez por mês; F1: quinzenalmente;

3. Você acredita que as TIC podem contribuir para um ensino e uma aprendizagem mais significativa? Justifique:
( ) $\operatorname{Sim}$
( ) Não

Respostas: C1: sim, as aulas se tornam mais atrativas para os alunos;

C2: não respondeu;

Q1: sim, porque através das TIC os conteúdos são explorados de uma forma mais dinâmica;

Q2: sim, pois as TIC complementam paralelamente o conhecimento repassado em sala de aula;

B1: sim, por oferecer grande informação e conhecimento de muitos assuntos;

B2: sim, sempre que temos algo novo ajuda na preparação das aulas;

F1: sim, desde que ela seja usada como apoio pedagógico e não como única referência;

4. Quais sugestões você daria para a melhoria do portal dia-a-dia educação? E para a formação de professores para utilização deste recurso didático?

Respostas: C1: um profissional que auxiliasse o professor no laboratório;

C2 e Q1: não responderam;

Q2: monitor ou laboratorista/professor auxiliar no laboratório de informática e cursos preparatórios para aperfeiçoamento dos professores;

B1: monitor ou laboratorista;

B2: cursos para os professores conhecerem melhor;

F1: nas semanas pedagógicas deveriam oferecer treinamento aos professores; 


\section{DISCUSSÃO}

Pelas respostas obtidas na questão um, podemos destacarque o professor Q1 considerou o seu trabalho ótimo frente às TIC, os professores C1, Q2 e F1 disseram fazer um bom uso e os professores C2 e B2 afirmaram ter um desempenho regular. Sabemos que a auto-avaliação não é uma tarefa simples, Luckesi (2005) considera a auto-avaliação como um recurso fundamental de crescimento para todo ser humano. Segundo o autor, um sujeito que não tenha autocrítica sobre si mesmo e suas ações, nunca mudará de posição, portanto todas as nossas condutas dependem de nossa autocrítica.O papel do docente é fundamental na implantaçãode qualquer processo de mudança relativo ao sistema de ensino, pois sem aconscientização, adesão e participação dos professores, qualquer tentativade diferentes abordagens não terá êxito (LEAL, 2004).

Analisando a segunda questão pudemos verificar que 43\% dos professores entrevistados são virtualmente participativos, acessando o Portal dia-a-dia Educação pelo menos uma vez por semana e $57 \%$ o acessam pelo menos uma vez no mês, lembrando que segundo Setton $(2010$, p.104) " os suportes das TIC estruturam uma nova ecologia cognitiva nas sociedades da atualidade". Portanto, nós professores não podemos nos excluir das TIC disponíveis pelo governo do Paraná pelo Portal dia-a-dia Educação.

Percebemos através da questão três que os professores acreditam na contribuição das TIC para um ensino e uma aprendizagem mais significativos, justificando que sua utilização pode tornar as aulas mais atrativas, explorando os conteúdos de uma forma mais dinâmica e abrangente; complementando paralelamente o conhecimento repassado em sala de aula e na preparação das aulas, desde que ela seja usada como apoio pedagógico e não como única referência, conforme afirma o professor de física (F1).

Dentro deste novo contexto de ensino a utilização das TIC, pode contribuir de forma significativa para o ensino e a aprendizagem, porém, o papel da informática deve ir além de professores treinados para fazerem uso da racionalidade instrumental para transferir conhecimentos e, sim, utilizá-la para aproximar o educando da realidade social, pois "a questão central não está na mudança do ensino tradicional para os mediatizados por tecnologias, mas na transição de uma educação e uma formação estritamente institucionalizada para uma situação de troca de saberes (LÉVY, 1994, p. 34)".

Na proposta didática para favorecer aprendizagem significativa, os Parâmetros Curriculares Nacionais recomendam que o professor deva levar em consideração o conhecimento prévio que os alunos possuem sobre recursos tecnológicos e o conteúdo. A partir daí ele deve planejar sua aula 
em função dos objetivos e os conteúdos de aprendizagem, utilizando-se dos recursos tecnológicos para problematizar os conteúdos e criar ambientes de aprendizagem que possibilitem ao aluno resolver problemas, ter iniciativa e criar soluções. A ideia é que o aluno adquira conhecimento de forma agradável, em um ambiente prazeroso (TERUYA, 2006).

Na última questão percebemos que os professores não apontam sugestões para melhoria do Portal dia-a-dia Educação, mas enfatizam que precisam se aperfeiçoar com cursos e treinamentos que possam ser oferecidos nas semanas pedagógicas e também relatam a necessidade de se ter profissionais que tenham capacidade de auxiliá-los no laboratório de informática.

Sabemos que ser professor na educação básica não é tão simples assim, pois além de preparar e ministrar suas aulas ele temmuitas outras tarefas a cumprir, portanto, esta falta de apoio ao professor, desvalorização profissional e classes com turmas numerosas estão provocando o desencanto e o mal-estar docente, pois ele está sendo visto como o grande responsável por todos os problemas da sala de aula (TERUYA, 2006).

\section{CONCLUSÃO}

Não podemos negar que permeia entre nós que o foco da qualidade de ensino e do sucesso da aprendizagem estádiretamente ligado à atuação do professor em sala de aula e em suas atividadesacadêmicas. Porém, quando nos direcionamos a utilização das TIC na educação, o foco da aprendizagem passa a ser centrada no educando, portanto, a internet deve ser vista como um novo meio de expressão, como um veículo de diálogo e construção de novas amizades, um local de tolerância e liberdade de expressão para os que criam e produzem a cultura virtual, bem como para receptores dessas novas linguagens. Pois é nesse espaço que o indivíduo estimula-se para produzir, escrever e ler a produção dos outros, tornando-se construtor do seu próprio conhecimento.

Portanto, a auto-avaliação é um passo muito importante para o crescimento profissional, pois quando o professor é capaz de fazer uma autocrítica sobre o seu trabalho ele será capaz de redirecionar sua conduta, mudar suas ações e conscientizar-se que precisa ir de encontro às TIC oferecidas pela sociedade da informação.

Percebemos que os professores entrevistados acreditam que as TIC disponíveis no Portal diaa-dia Educação podem levar a uma aprendizagem significativa, através de aulas mais atrativas, promovendo motivação nos alunos, sendo que os conteúdos são explorados de uma maneira mais dinâmica e abrangente. Porém, destacam que precisam auxílio de um profissional no laboratório de 
informática e de cursos e treinamentos para poderem atualizar-se, pois se senteminseguros e despreparados frente às TIC disponíveis no Portal dia-a-dia Educação.

\section{REFERÊNCIAS}

COOL, C; MONEREO, C. Psicologia da educação virtual: aprender e ensinar com as tecnologias da informação e da comunicação. Porto Alegre: Artmed, 2010.

GODOY, A.S. Pesquisa Qualitativa. Tipos Fundamentais. Revista de Administração de Empresas. São Paulo, v.35, n.3, p.20-29. mai/jun. 1995.

LEAL, M.G. Currículo baseado em competências: uma proposta paraos cursos de graduação em Engenharia". In: WORLD CONGRESS ONENGINEERING AND TECHNOLOGY EDUCATION, 1, 2004, Guarujá, SP.Anais eletrônicos. Guarujá, SP: [s. n.], 2004.

LÉVY, P. As tecnologias da inteligência: o futuro do pensamento na era da informática. Rio de Janeiro: Ed.34,1994.

LUCKESI, Cipriano Carlos. Avaliação da aprendizagem: visão geral.2005a. Disponível em <http://www.luckesi.com.br/artigosavaliacao.htm>. Acesso em: 17 agosto. 2013.

Paraná, Secretaria de Estado da Educação. Superintendência da Educação. Departamento de Ensino Médio. Diretrizes Curriculares da Rede Pública de Educação Básica do Estado do Paraná. Química. Curitiba: SEED / DEM, 2006.

PERRENOUD, P. Dez novas competências para ensinar, tradução Patrícia Chittoni Ramos. Porto Alegre: Artmed, 2001.

PIMENTA, S. G.; ANASTASIOU, L. das G. C. Docência no Ensino Superior. 2. Ed. SãoPaulo: Cortez, 2005.

PROGRAMA DAS NAÇÕES UNIDAS PARA O DESENVOLVIMENTO (PNUD). Projeto BRA/03/036 educação básica e inclusão digital no estado do Paraná.,2007. Disponível em: <http://www.pnud.org.br/arquivos/arqui1084291939.zip> Acesso em: 15 abr. 2013.

Secretaria de Estado da Educação. Portal dia-a-dia Educação. Disponível em: www.diaadiaeducacao.pr.gov.br. Acesso: em 18 abr. 2013.

SETTON, M.G. Mídia e Educação. São Paulo: Contexto, 2010.

TERUYA, T.K. Trabalho e educação na era midiática: um estudo sobre o mundo do trabalho na era da mídia e seus reflexos na educação. Maringá,PR: Eduem, 2006.

VALENTE, J.A. O computador na sociedade do conhecimento. Cadernos Informática para a Mudança em Educação. Brasília: Ministério da Educação/SEED, 1999. Disponível em: http://www.proinfo.gov.br/ftp/pdf/livro02.zip>. Acesso em: 15 abr. 2013. 